\title{
Hybridity of the Self Between Desh (Home) and Pardesh (Abroad)
}

\author{
Ileana-Mihaela Motroc (Popescu) \\ Ovidius University, Constanta, Romania
}

\begin{abstract}
This paper examines the formation of the self in the context of emigration and the Indian individual in the Anglo-American space, in the novels: Fasting, Feasting by Anita Desai, The Inheritance of Loss by Kiran Desai, and The Namesake by Jhumpa Lahiri. The analysis focuses on exploring the way in which the hyphenated self is constructed under the influences of dialogical negotiation of desh and pardesh in the context of racism, global-local (glocal) specificity, becoming authenic under the presure of home memory, diaspora ethnicity and mimicry. Is reterritorialization and acculturation successful for the hybrid self? The answers is to be found by the characters of the novels and shown in instances of self expression and integration. Arun, the Indian guy, from Anita Desai's novel left India for studying in America. During the summer, he is accommodated to an American family. The clash between the two cultures, traditions, and customs is felt as a huge breakage, which leads to desintegration and alienation. Biju and Harish-Harry from Kiran Desai's novel go to America for a better living, and they succeeed in finding a job at a bakery. The impact of racism is higher in the lower strata of the society, thus their chances to integration are lost; Biju decides to return home, while Harish-Harry ends in a hyphenated self and a dissatisfied living. In The Namesake, Ashoke and Ashima, the Indian emigrants husband and wife, experience a different reshaping of identity. Ashoke works as a university assistant, while Ashima is a housewife. For him, America is a space for affirmation and self-verification, while for his wife, the space becomes a ghetto where she feels lonely and marginalised. Therefore, in the formation of the self there are many coordinates which should be taken into consideration and above this, their impact over the immigrant is different from case to case depending on many factors.
\end{abstract}

Keywords: hyphenated/hybrid self, desh and pardesh, reterritorialization and acculturation

\section{Introduction}

This article studies the hybridity of the self and its reformation from three perspectives: space, society, and memory. The characters of the books migrate from India to America, via Great Britain in some cases, in others they remain in Britain or go straight to America. The struggle for integration in both spaces seems to be the same, as the plots of the novels show. The questions to which the article tries to answer are: Which is the impact of space and memory over the immigrant? Are these obstacles in the process of reshaping the self? Should the old space and memory be integrated in the new spatial patterns, or simply deleted for good? What is the meaning of hyphenated identity and what are its effects on the immigrant Indian?

Ileana-Mihaela Motroc (Popescu), Ph.D. student at Ovidius University, English teacher at the Mircea cel Bătrân National College, Constanta, Romania. 
The article analyzes the ways in which the narratives in the novels under scrutiny-Anita Desai's Fasting, Feasting (2000), Kiran Desai's The Inheritance of Loss (2006), and The Namesake by Jhumpa Lahiri (2011) - represent the characters' distorted identities, shaped by their conflicting and hybridized selves. The interiorized spaces that Arun (in Anita Desai's Fasting, Feasting) and Harish-Harry (in Kiran Desai's The Inheritance of Loss) inhabit are shaped by their conflicting selves, constantly pendulating between the inheritance from home (desh) and the new culture of abroad (pardesh). While attempting to advance a theory of inwardness shaped by locality — as expressed through narrative — to explain the ways in which Indian immigrants of varying regional, religious, and linguistic backgrounds experience what it means to belong, I will show how hybrid ethnicity is produced through the relationship between domestic racial formations and global movements of class and capital. Discussing the re-shaping of Indian cultural identity through Bollywood songs and dances, Hindu-centric iconography, and beauty pageants in American society, Bakirathi Mani observes that "These acts of cultural preservation reproduced a homogeneous idea of nationhood - that is, one constituted through dominant religious, ethnic, and linguistic ideas of what it means to be 'Indian"' (Mani, 2012, p. 2). Rather than ascertaining a "homogeneous idea of nationhood", as I argue, the characters in the novels discussed in this chapter reveal the inconsistencies and conflicting selves of their personality (Arun, Harish-Harry, Gogol, Jemubhai, Uma, Gyan, and Ashima), when confronted with what they perceive as an almost hostile dominant culture.

Identity has been thoroughly researched by psychologists, sociologists, and anthropologists, while many perspectives have been offered on self and identity. In the construction and reconstruction of selfhood, there are two important strands which should be reflected upon: social identity and self identity. The former refers to all the influences which a given society has on an individual, starting from power (Foucault, 1980, p. 34), going on with controlled autonomy, and ending with the shaped behaviour through assuming roles (Stryker \& Serpe, 1982, pp. 199-218). The latter-self identity-demonstrates that a person always needs self-verification with a certain model or standard in order to gain recognition and self-esteem. Moreover, the process of self-reflection in the production of literary sociological and behavioural processes is mirrored through the intersection of the characters. In this way, the characters' personalities are relevant interfaces that connect the fictional worlds and spaces of the novels to the real worlds in which these former-immigrant authors evolve. The writing process is, thus, for these authors, a sort of ritual during which they attempt to come to terms with their own selves through creativity.

Space and memory of the lived-in space are other two key elements in the formation of the hybrid identity. In the novels, the old space of home is brought into the new space of adoption in the form of virtual images of everything which stands for the specificity of a given space: people, customs, traditions, rituals, religion, etc. The memory of all those things becomes traumatising and an element of disturbance in the construction of the self. The more connected an Indian would be with the home elements, the less integrated he would be. That is why the women from the novels perceive the longing after India more powerfully than men do, because they are the preservers of home traditions: puja religious festivals, home cuisine, dress-saris-and other specific cultural elements, such as bindis and bangles. The plots of the novels are focused as an open eye to the world of the immigrant, caught between two spaces, struggling to match the foreign standards.

The meeting of two cultures and the wish for integration and reconstructing the self of the third-world people was one of the important themes of many novels written by Indian novelists who were themselves immigrants in a hostile land. Anita Desai's Fasting, Feasting deals with insights in the life of an Indian family with three children, one of whom immigrated to America. The plot snapshots different scenes from the life of 
an upper-caste family, kshatrya, and unveils, event by event, their beliefs and traditions, as well as the woman's place in family and society. To this life, Desai opposes the life of the Indian son who immigrates to America for studies. There, he lives with an American family during the summers. Thus, he comes across American culture. Year by year, he realizes that he cannot live his life there, as he cannot adapt to the American way of living. One example of broken communication and lack of understanding between Arun and the family he visits is when they take their meal together one day. Mr. and Mrs. Patton, with their son and daughter, are not only meat eaters, but highly addicted to consumption of all goods, necessary or not, and they eat unhealthy food in high quantities. On the other hand, Arun eats vegetarian, does sports, and avoids useless consumption.

The conversation among them during the barbecue at which Arun has been invited is relevant both for the cultural shock and for the reshaping of the self. Meals are in themselves rituals and embodiments of culture and traditions. Arun and the American family, at barbecue, have the possibility to express their customs and their social identity. Arun is tempted by his hosts to renounce his beliefs, his identity, and his vegetarianism for the sake of a better integration. He chooses the middle path: to join the meal, so that not to be rejected by his hosts, but to keep his ethnic identity. Therefore, his self passes through a shifted identity, oscillating between the desh identity and the pardesh adherence. Mr. Patton, the American host, calls everyone outside for a grilled meat, including Arun, the Indian guest. "Isn't anyone interested in bar-be-cue" (Desai, 2000, p. 163)? The inadequate spelling of "bar-be-cue" emphasizes the incalculable distance between the living and eating space of the American family and Arun's dietary habits. This strange pronunciation and spelling configure a distinctive cultural space in which the American family is characterized by their eating practices, which appear to Arun just as wrong as the spelling of "bar-be-cue". In addition, the Americanized lopsided pronunciation suggests a deformation of the English language - as compared to the British version which Arun had experienced at home, when blended to his native language.

Memory, narration, and traditions are the constituents of maladaptation and fragmentation of the self. The first generation of immigrants still preserve their customs, habits, and celebrations, which are usually manifested at home. They would gather at one person's place and revive their imagined India. Thus, one part of their soul remains Indian, while the rest struggles for integration. The renovated memories and the narratives of home help immigrants define themselves and their origin. Whatever is original and local is brought into global; thus, Indians feel unique and not alienated. Their stories, memories, and traditions become a national heritage which is transmitted to the second and third generations. However, India is not the same for all the generations of Indians. The later in time the descendents are, the less they love and praise India. The immigrants' sons and grandsons feel more and more reluctant to fulfil the rituals of their nation, as they are ashamed of their third-world origin ${ }^{1}$. The new generation does not feel nostalgic after India, as their parents do. They are not sensitive to their parents' cultural manifestations-pujas, Hindu festivals, important life-events rituals; these are only reminders of their coming from a third-world country, in search for integration. The younger generation, such as Arun's, tries to get rid of everything which unmasks their origin; in this way, they think that they might avoid exclusion and discrimination. Thus, memory, narrations, and traditions have a different impact from generation to generation in the hybridisation of the self.

In the formation of the self, a lot of other factors are involved. A person cannot create his/ her personality, identity, way of being, beliefs and behaviour without interacting with other people. On the other hand, the rules,

${ }^{1}$ Alfred Sauvy, a French demographer and anthropologist, first coined the term (14). 
traditions, politics of the state leave a heavy mark on the self. The immigrants' status abroad is highly important for the formation of personality. It makes a huge difference to be a native or an immigrant. The discriminatory acts make the newcomer more subdued and restrained in expressing his/her personality. Hubert Hermans suggests "the dialogical model" (1996, pp. 31-50) in the understanding of the self. He claims that an immigrant passes through multiple negotiations with the state and other people, until he achieves a certain identity (Hermans, 1996, p. 35). Nevertheless, this construction of the self is not static and unalterable. It changes over and over again, according to the influences it receives. In the case of Arun's adaptation to his university environment, he can neither be attracted by the freedom of his pot-smoking roommate from Louisiana, nor reject his co-nationals from India, who found an escape from social marginalization by immersing themselves in pastimes that reminded them of their native land. Their selves, therefore, were fragmented and re-shaped out of a multiplicity of infinitesimal parts that recombined like DNA molecules implanted into a foreign body. Arun is unable to accept the Americans' consumerism and liberalism, but he also views ironically his Indian friends' congregation to watch Bombay movies and listen to Indian tapes.

Another Indian writer, Kiran Desai (Anita Desai's daughter) explores the intertwined threads of the self caught between Indian traditions and Anglo-American culture. Her book, The Inheritance of Loss, "is a saga of a community profoundly shaped by the colonial past, by conflicts rooted in social, class, and ethnic differences, and by migration and dislocation in an increasingly globalized world" (Hestetun, 2010, p. 85). Biju, the son of the judge's cook, immigrated to New York, for a better living. There, he works illegally at a bakery, coming into contact with Native Americans and other ethnic groups-people who have the same status as he has. Discrimination and cultural differences impede his adaptation and reconstruction of the self. Harish-Harry is another Indian working there, who befriended Biju. His name is purposely hyphened to underline the hybrid self formed out of the two mixed identities, the Indian one-Harish, which is placed first in the name sequence to suggest his origin, and the American identity illustrated through the second name, Harry. Even the same capital letter has a meaning. This sameness shows that Harish will try to appropraiate whatever can match his identity so that to form a unitary self.

The Namesake by Jhumpa Lahiri is described by post-colonial critic Doris Einsiedel as using "educational violence as an impulse for escape and the wider legacy of colonial history merge with contemporary tragedy in the impulse for emigration" (2010, p. 35). Ashoka and Ashima, two Indian immigrants in America, have a son, Gogol, and a daughter. The son is named after the Russian writer, Nikolai Gogol, whose novel his father was reading while he had a terrible train accident. The young boy is frustrated by being the carrier of another ethnical group name in America. He perceives this as an impediment to his integration in the American society. During the world literature class, Gogol's American teacher uses unveiled irony to mark the similitude between the name of the Russian novelist they were studying and the unassuming Indian-origin student sitting in class: "The following day, Mr. Lawson writes 'Nikolai Vasilievich Gogol' in capital letters on the board. [...] 'Not your ordinary guy, Nikolai Gogol,' Mr. Lawson says” (Lahiri, 2011, pp. 90-91). Gogol feels pointed, even if the teacher's intention was not necessarily a direct mockery, because he is prejudiced for being a foreigner in their community, as Russians are. The Indian immigrant's self-conscious embarrassment is transformed into anger at the teacher who made the allusion: "Warmth spread from the back of Gogol's neck to his cheeks and his ears. Each time the name is uttered, he quietly winces. [...] He feels angry at Mr. Lawson suddenly. Somehow he feels betrayed" (Lahiri, 2011, pp. 90-91). The feeling of betrayal comes from a tacit, untold agreement that the teacher will not unmask Gogol's identity, as he does not feel prepared to step forward. 
Immigrants use mimicry unconsciously in order to resemble the dominating host people, the successful people from the country they live in. On the one hand, they admire them for their smooth ascension but, on the other hand, they despise them for using racism and discrimination in relation to immigrants. The newcomers yearn for recognition, acceptance, and integration and for this they use all the necessary strategies in order to become part of the nation they live in. Mimicry is one of them- the easiest way to look like the ones who rule, in order to fit in their society. The negative effect of mimicry is lack of authenticity, because the person's specificity-traditions, clothes, behaviour, beliefs-combines with the foreign cultural heritage. The combination of whatever is specific to a certain country or people with other features from the world creates what the sociologist George Ritzer calls the glocal. He claims that "Glocalization involves the integration of the global and the local, producing a unique outcome wherever in the world it occurs" (2007, p. 118). Ritzer's socio-economic perspective of globalisation can be interpreted in the cultural frame, as well. This means that, in this global world, neither cultures nor individual selves can remain pure.

Identity is in a continuous change because of its intricate constituency, as it is influenced by other people, community, and society. Moreover, a person is under the influence of others-family and friends-of the place he/she lives in, of the state institutions, of the historical events which took place along years, of the collective memory, of the state power and religion, and not lastly, of his or her imagination and inner transformations. This concoction of constituents becomes an important part in the formation of identity, provided that the outside influences are internalized. Sociologist Manuel Castells defines identity, in connection with globalisation, as "the process of construction of meaning on the basis of cultural attribute" $(2010, \mathrm{p}$. 6). The changing of the place of living leads to a reconsideration and reconstruction of all pillars of personality. In this new context, each constituent takes another meaning. Memories of the home-place become traumatizing and carve the path to alienation. Culture, traditions, and religions are manifested secretly in Diaspora places, as a reminiscence of the immigrants' past. All these result in a plurality of identities. Indians, at home or with other members of Diaspora, behave in a more sensitive way, more openly and communicatively, while with the white authorities from work, or with society in general, they behave stiffly and in a restrained manner.

The main distinction to be observed in understanding identity is between social identity/ies and personal identity/ies. In both cases, the fulfilment of certain roles inside different groups-family, ethnicity, politics, or religion-lies at the foundation of identity formation, provided that those roles are internalized. On the other hand, the perceptions and views about life are relevant in shaping a person's identity. Burke and Stets define a person's identity as being "based on a view of a person as a unique entity, distinct from other individuals, [and] on the qualities or characteristics individuals internalize as their own, such as being more (or less) controlling or more (or less) ethical" (2009, p. 112). In other words, outside influences are passed through a personal filter of values, then, internalized, resulting in specific behaviour and a certain way of being. Nevertheless, in the formation of identity, apart from the output-culture, society, family, and personal perceptions-there is the verification with a standard identity. This self-verification is the feed-back which a person gets from his/her peers, family, and society. An individual will perceive himself/herself as an outsider without the others' praise and appreciation, which will affect the person's identity. Burke and Stets consider that the positive answer to identity-verification is self-esteem, which is made up of "self-efficacy or a sense of competency, self-worth, or a general sense of being found worthy and valuable, and self-authenticity, or the feeling that one is being one's true self" (2009, p. 117). The immigrants' maladaptation and alienation come from this negative feed-back of self-verification. The lack of appreciation which they get is seen in the jobs to which they have access. They 
can hardly be employed at the level of their capacities; they usually do physical labours, through which they serve the others. This has an unfavourable impact on their identity, as they feel rejected, not wanted, and undervalued.

A separate branch of social identity is ethnic identity. This is formed before social identity, in the case of first-generation immigrants and after social identity, in the case of their off-springs. This is because the newly-arrived emigrant has a strong bond with his/her native country, while, for his/her sons and daughters, India is the second country, their parents' place. Children do not identify with it, and sometimes they feel embarrassed by their third-world origin, under racist influences. Ethnic identity abroad is formed through the means which were brought in the host country, such as puja's objects, festival rituals, and other elements of cultural heritage. This is possible in a cultural pluralism, where immigrants are assimilated and allowed to manifest themselves. The most important constituents in the creation of ethnic identity are: cultural, political, and religious manifestations, expressed in the consumption of goods and Hindu beliefs. The materialization of this ethnicity consists in the commercialization of certain specific products, such as: "food, jewellery, clothing, videos and music recordings, religious paraphernalia, books, newspapers" (Parekh, Singh, \& Vertovec, 2003, p. 172). These things make immigrants feel the bond with their home country more powerfully and help them avoid alienation. In addition, these material elements become part of their cultural identity and they are an expression of the self, as Indians. Some of these specific objects are: masala dosa (Indian food), bangles (Indian bracelets), sari (female Indian cloth), bharatanatyam (Indian classical dance style), objects for puja (the religious service), Vedas, Upanishads (Hindu religious books), and others. When other people see one of these elements to another person, he/she will be able to figure out the person's ethnic identity.

The impact which the ethnic group can have over the immigrant is analyzed at large in Kiran Desai's book. She presents at least three main parallel plots featuring immigrants: the one of Gyan, the Nepali young man who emigrated from Nepal to India, of Biju, the Indian who immigrated to America and of Saeed, the African man, an immigrant in America. Biju identifies himself, in many cases, with Saeed, as he admires him for his charismatic way of being. "Biju's sympathy for Saeed leaked into sympathy for himself, then Saeed's shame into his own shame [...]" (Desai, 2006, pp. 98-99). These harsh conditions in which immigrants were forced to live, at least at the beginning of the twentieth century, left an imprint on their personality and on their reforming identity. They identify with one another and see themselves through the others' eyes. They appropriate the parts of the personalities of the ones who have succeeded more in adaptation. Through imitation, immigrants tend to resemble one another. When Saeed and Biju are asked to help other emigrants, they are reluctant, as they themselves can hardly survive. The scarce conditions of living alter their personalities and shape them in another way than it would have been at home. All these frustrations of living in poor and sometimes inhuman conditions changed their behaviour. They left aside their altruistic nature, as they could not help others anymore, since they were themselves in need. Their personality and identity took another course, separate from their ethnic beliefs, because they had to survive.

Not only are person, society, and ethnic group important in forming one's identity, but also the space in which that person has lived or lives has its strong effects on identity construction. In "Interrogating Identity", Homi Bhabha claims that identity is connected with "a spatialization of the subject that is occluded in the illusory perspective of [...] the third dimension of the mimetic frame or visual identity" (1990, p. 192). The individual leaves his/her native place for another one, where he/she does not feel as if he/she were at home. The space in which the person lives is not the same as the imagined one, as he cannot perceive the second space as 
home. This imaginary place, the place of remembrance and memory, is denoted as a "supplementary third space [which] introduces a structure of ambivalence" (Bhabha, 1994, p. 217). Homi Bhabha coined the term of "third space", which designates the "hybrid" place, in his book The Location of Culture (1994, p. 55). He refers to it as having "a structure of ambivalence", due to the absence of a real space and of in-between-ness; this is neither the first space - the home country, nor the second place-the adopted country, but the third one-which is conceived of memories from the deserted place located in the new space.

Memories have the role of healing, and of creating a bridge between past and present with the final purpose of reconstructing the self for a better integration in the new space. They have to be wisely placed in human consciousness, so that not to affect the new identity and the roles which the immigrant is expected to fulfil. In most cases, memories are a painful remembrance of the lost dear land, community, traditions, and customs. The ones who cannot encapsulate that part of their lives will end in maladaptation, triggered by a failure of dealing with past bounds. On the other hand, those who are at the other extreme, who deny their past, their memories, their identity with the purpose of creating a new one for a better integration, end in fabricating a manufactured identity which has no roots or stability. In Memory, Narrative, Identity, Nicola King claims that "Memory can create the illusion of a momentary return to a lost past; its operations also articulate the complex relationship between past, present and future in human consciousness" (2000, p. 11). Memory is associated with an illusion, as it is an imaginary recollection of past events, people, and things. This leaves an imprint on human consciousness, as everything which comes as new acquisition should match and integrate the old existing pattern. The lack of lookalike between the two major experiences from homeland and host land will bring alienation and grief to the immigrant. Those who succeed in matching and uniting the two worlds will get relief in their consciousness and the hybrid self will lead to a successful integration.

The two Indian immigrants, Ashoke and Ashima Ganguli, husband and wife in Jhumpa Lahiri's The Namesake, pass through the process of integration and reformation of the self differently. Ashoke works as an assistant professor in America, while his wife remains a housewife. He is praised and valued for his work, whereas his wife cannot achieve self-esteem and high standard in self-verification with the foreign values. He plays the role of an employee in an American institution, while his wife has only the role of a preserver of Indian traditions-as she goes on cooking traditional Indian food, accomplishing puja religious services, communicating with other Indian women from Diaspora. As a result, Ashoke succeeds in integrating smoothly, in adjusting his self to the American requirements and in pushing his memories backwards into his subconscious. In opposition with him, there is Ashima; she does not have the chance to get a job, to communicate with American people, to get the feeling of being welcomed; thus, she ends up in a deep grief of solitude, of longing after India, of nourishing herself with past memories, wishing to return to India. Her identity is deeply shaken by the tormenting memories which do not let her cope with the new space. The description of the integration of husband and wife in the new space is achieved in a contrastive manner:

The Gangulis have moved to a university town outside Boston. [...] Ashoke has been hired as an assistant professor of electrical engineering at the university. [...] The job is everything Ashoke has ever dreamed of. [...] For Ashima, migrating to the suburbs feels more drastic, more distressing [...] (Lahiri, 2011, pp. 48-49)

Ashoke has the opportunity to leave aside his memories because of his preoccupations to reach the given standards, while Ashima is not integrated as a worker in American community. He cures his wounds from departing India through new roles, new challenges and targets, while Ashima remains isolated in her world of 
Indian womanhood, as she cannot find any link between her tradition and the American one. When her husband decides to buy cheaper things for their house from a second-hand shop, "Ashima is reluctant to introduce such items into her home, ashamed at the thought of buying what had originally belonged to strangers, American strangers at that" (Lahiri, 2011, p. 52). The lack of acceptance is from both sides; Ashima feels that American people will always regard her as a foreigner, while she can never have the feeling of being at home. This rejection comes from the difference in cultures, mentalities, and preconceived thoughts. All these lead to a lack of adaptation and of forming a successful identity.

Memory has a huge impact on the formation of identity, as it carves one's identity through the changes imposed on affectivity. Once a person leaves his/her birthplace, community, and traditions, this feeling of missing something important shapes a certain attitude. This haunting memory of the past is confronted with the hosts' racial behaviour, which leads to a gap between the inner and the outside world; and between the two identities. In "Identity" from Geography and Memory, Owain Jones and Joanne Garde-Hansen support the idea that "Family life, work life, and all their spatiality and materiality (both past and present) are complex and anticipatory in the practice of identity" (2012, p. 25). The pattern of identity formed in the previous space leaves a mark on the individuals' behaviour: The immigrant tends to compare everything with what he/she has lived in the past and the differences are felt as painful changes and distressful experiences in the achievement of integration. Jones and Garde-Hansen explain the "anticipatory" attitude through "an affective state of becoming", at whose basis lies "grief" as "a form of memory" (2012, p. 25). Even if the home they left was from the third world and immigrants left it for a better place, there is a rupture from whatever was well known and the fear of the unknown.

\section{Conclusions}

Identity - as represented in the novels discussed in this article - is a complex constituent of a character's personality, which has been described from the perspective of various domains-psychology, sociology, philosophy, and literary perspective. The most important elements in the formation of a character's identity, as I argue, are space - as home or as a foreign land, power-a social construction in the form of an obstacle in the creation of identity, and the memory of the former identity, space, and society. Together with these identity-shaping aspects, there are many additional influences which are involved in the shaping of the self, such as individual perception, imagination, and even certain oedipal tendencies. Space and power divide characters into two separate groups, according to the difficulty in achieving an autonomous and authentic identity. Those who remain in their native place pass through a smoother process of forming their inner self, while the ones who prefer to immigrate for a better financial and social status experience a more difficult pathway in shaping their identity.

Indian characters in these novels are caught between two worlds and have to go on an intricate path towards integration and formation of the self. They have to deal with the burden memory of whatever their absent Indian topos creates, while striving to achieve a certain standard in a hostile environment. Female Indians, such as Ashima and Uma, have a more difficult task, as they have to lead the struggle for equal rights with their male partners or father. The passage from personal memory to ethnic memory and then to collective memory is done for the preservation of the Indian heritage and for the formation of an authentic identity; still the transfer among all these entities is not easily done. When there is too much preservation of nationhood, there is less degree of integration. The most difficult task regarding the reformation of the self in these 
characters consists in integrating the old memories in the new experiences, so that to quieten the afflicted consciousness. These torments are visible in the novels written by Indian immigrants, who seem to have become spokespersons for their ethnic group or sex.

\section{References}

Bhabha, H. K. (1990). Interrogating identity, the postcolonial prerogative. In D. T. Goldberg (Ed.), Anatomy of racism (pp. 188-209). Minneapolis: University of Minnesota Press.

Bhabha, H. K. (1994). The location of culture. London and New York: Routledge.

Burke, P. J., \& Stets, J. E. (2009). Identity theory. New York: Oxford University Press.

Castells, M. (2010). The power of identity. Chichester: John Wiley \& Sons.

Desai, A. (2000). Fasting, feasting. London: Vintage.

Desai, K. (2006). The inheritance of loss. England: Penguin Books.

Einsiedel, D. (2010). Colonial recall in Desirable Daughters and The Namesake. In J. C. Kardux and D. Einsiedel (Eds.), Moving migration: Narrative transformations in Asian American literature (pp. 19-44). Berlin: LIT.

Foucault, M. (1980). Power/knowledge. (C. Gordon, Ed.; C. Gordon, L. Marshall, J. Mepham \& K. Soper, Trans.). Hemel Hempstead: Harvester Wheatsheaf.

Hermans, J. M. H. (1996). Voicing the self: From information processing to dialogical interchange. Psychological Bulletin, 119, 31-50.

Hestetun, Ø. (2010). Migration in Jasmine and The Inheritance of Loss. In J. C. Kardux and D. Einsiedel (Eds.), Moving migration: Narrative transformations in Asian American literature (pp. 81-94). Berlin: LIT.

Jones, O., \& Garde-Hansen, J. (2012). Identity. In O. Jones and J. Garde-Hansen (Eds.), Geography and memory: Explorations in identity, place and becoming (pp. 25-44). England, Hampshire: Palgrave Macmillan.

King, N. (2000). Memory, narrative, identity: Remembering the self. Edinburgh: Edinburgh University Press.

Lahiri, J. (2011). The namesake. London: Fourth Estate.

Mani, B. (2012). Aspiring to home: South Asians in America. Stanford: Stanford University Press.

Parekh, B., Singh, G., \& Vertovec, S. (2003). Culture and economy in the Indian diaspora. London and New York: Routledge, Taylor \& Francis Group.

Ritzer, G. (2007). The globalization of nothing 2. London: UK Sage Publications Ltd.

Sauvy, A. (1952). Trois mondes, une planète (Three worlds, one planet). Société Démographie: EnVrac, (118), 14.

Stets, E. J., \& Burke, P. J. (2000). Identity theory and social identity theory. Social Psychology Quarterly, 63(3), $224-237$.

Stryker, S., \& Serpe, R. T. (1982). Commitment, identity salience, and role behaviour: Theory and research example. In W. Ickes and E. S. Knowles (Eds.), Personality, roles, and social behaviour (pp. 199-218). New York: Springer-Verlag. 